Journal of Social, Evolutionary, and Cultural Psychology

www.jsecjournal.org -, 2009 - 3 (1): 29-48.

Original Article

\title{
INDIVIDUAL DIFFERENCES AND SOCIAL CONTEXTS: THE ABSENCE OF FAMILY DETERRENCE OF SPOUSAL ABUSE IN SAN JOSÉ, COSTA RICA
}

\author{
Aurelio José Figueredo \\ Department of Psychology \\ University of Arizona, Tucson \\ Eiliana Montero Rojas \\ Instituto de Investigaciones Psicológicas \\ Universidad de Costa Rica \\ Martha Frías Armenta \\ Departamento de Derecho \\ Universidad de Sonora \\ Víctor Corral Verdugo \\ Departamento de Psicología y Ciencias de la Comunicacino \\ Universidad de Sonora
}

\begin{abstract}
Independent samples of 261 women and 138 men in San José, Costa Rica, were screened for involvement in committed sexual relationships during the past year, but not with each other. Females reported on victimization by spousal aggression and males on perpetration. Family structure parameters were also assessed: (1) local density of female kin, (2) local density of male kin, (3) social support provided by local kin, (4) socioeconomic status of close kin, and (5) "culture of honor" $(\mathrm{COH})$ revenge ideology. Previously documented effects of partner mate value on spousal abuse were crossculturally replicated, but the interactive effects of male kin density previously documented in Hermosillo, Sonora, did not predict family deterrence of spousal abuse in San José, Costa Rica. A recent cross-cultural survey had found that San José, Costa Rica, situated within a predominantly farming region, was relatively low in $\mathrm{COH}$ but that Hermosillo, Sonora, situated within a predominantly herding region, was relatively high in $\mathrm{COH}$. Thus, individual convictions, such as a personal code of honor, may be ineffective outside of a supportive social context. Individuals with high $\mathrm{COH}$, acting within a low- $\mathrm{COH}$ social context, were unable to project the influence they normally exert within a supportive, high- $\mathrm{COH}$, social context.
\end{abstract}

Keywords: Spousal Abuse, Family Structure, Family Deterrence, Culture of Honor, Mate Value

AUTHOR NOTE: Please address all correspondence to: Aurelio José Figueredo Department of Psychology, PO Box 210068, University of Arizona, Tucson, AZ 85721-0068. Email:

ajf@u.arizona.edu

(C2009 Journal of Social, Evolutionary, and Cultural Psychology 


\section{Individual Differences and Social Contexts: The Absence of Family Deterrence of Spousal Abuse in San José, Costa Rica}

The present paper reports a constructive replication of a previous study by Figueredo et al. (2001) on spousal deterrence of spousal abuse in Hermosillo, Sonora, México. In that study, independent samples of 128 women and 106 men were interviewed regarding their family structure, support, and conflict; females reported on victimization by spousal aggression and males on perpetration. Respondents were screened for involvement in a committed sexual relationship during the past year, but not with each other. Effects that had been previously documented by Figueredo \& McCloskey (1993) on spousal abuse of their partner's mate quality their partner's socioeconomic status were cross-culturally replicated. The following family structure parameters were also measured: (1) the local density of female kin; (2) the local density of male kin; (3) the social support provided by local kin; (4) the socioeconomic status of close kin; and (5) the "culture of honor" $(\mathrm{COH})$ revenge ideology of the respondents. The same interactions of local density of male kin that protected women from spousal abuse also empowered men to perpetrate it. The risk of spousal abuse was mitigated by the "sexual balance of power" between the family structures of potential victims and potential perpetrators. To summarize, women with higher local densities of male kin, higher degree of kin social support, higher close kin socioeconomic status, and higher $\mathrm{COH}$ or "revenge" ideologies, were found to experience significantly lower rates of spousal abuse. In contrast, men with higher local densities of male kin, higher degree of kin social support, higher close kin socioeconomic status, and higher $\mathrm{COH}$ or "revenge" ideologies, were found to actually perpetrate significantly higher rates of spousal abuse. Evidence was also found partially supporting several alternative hypotheses tested regarding local cultural and ideological mechanisms (Culture of Honor and Patriarchal Beliefs), major dimensions of psychopathology (Anxiety and Depression) and substance abuse (Alcohol), and indicators of general criminality (Permissive and Risk-taking Attitudes).

The fundamental reason that this constructive replication and cross-national comparison was required by the generative theory was because of the relevant sociocultural differences between San José, Costa Rica, and Hermosillo, Sonora. In a subsequent cross-cultural survey (Figueredo et al., 2004), San José, Costa Rica was found to be relatively low in $\mathrm{COH}$ whereas Hermosillo, Sonora, was found to be relatively high in $\mathrm{COH}$. This significant difference in $\mathrm{COH}$ was predicted by theory: San José, Costa Rica, is situated within what was traditionally a predominantly agricultural (farming) region, whereas Hermosillo, Sonora is situated within what was traditionally a predominantly pastoral (herding) region. Nisbett and Cohen (1996) have proposed that high $\mathrm{COH}$ is a virtually universal characteristic of herding (as opposed to farming) societies and their latter-day descendants. Our Latin American results provided further empirical and cross-national support for this hypothesis.

What motivated the specific targeting of the present study was that we predicted an absence of family deterrence of spousal abuse in low-COH societies, such as that found in San José, Costa Rica. Furthermore, we predicted that individual differences in $\mathrm{COH}$ would be ineffective outside of a supportive social context. Even individuals with

Journal of Social, Evolutionary, and Cultural Psychology - ISSN 1933-5377 - volume 3 (1) 2009. 
high $\mathrm{COH}$, when acting within a low-COH social context (e.g., San José), will not have the kind of influence that they normally exert within a supportive, high- $\mathrm{COH}$, social context (e.g., Hermosillo). The adaptive function of the threat of retribution is to serve as a behavioral deterrent (Nisbett \& Cohen, 1996; Figueredo, 2001). Therefore, it necessarily loses its signaling function outside of a social and cultural context where the threatening social signals documented by Nisbett and Cohen (1996) are recognized and acknowledged as such. As Dr. Strangelove phrased it in the movie of the same name, "Of course, the whole point of a Doomsday Machine is lost, if you keep it a secret! Why didn't you tell the world, eh?"

Of course, as with virtually any two societies, $\mathrm{COH}$ is not the only theoretically important difference between Sonora and Costa Rica. Sonoran society is also appreciably more socially conservative than Costa Rican society (García et al., 2002); Costa Rica is a generally more egalitarian society than México, sexually as well as socioeconomically. For example, in 2007, Costa Rica ranked $24^{\text {th }}$ in the UNDP's Gender Empowerment Measure (GEM), whereas Mexico ranked $46^{\text {th }}$ (United Nations Development Programme, 2007). The Gender Empowerment Measure (GEM) is a social indicator that measures the level of women's opportunities compared to men's in the three dimensions: political participation, economic participation and control over economical resources. Furthermore, it appears that Costa Rican society is currently experiencing important changes in the relations between men and women (Vega-Robles, 2001, 2007). In a recent a trans-generational study dealing with the cultural construals of the female and the male identities in three types of Costa Rican families, Alvarez (2007) reports that sexual identities are in a process of transformation within these families. She also reports the increasing fragility of the culturally construed male sexual identity in Costa Rica:

“...These situations seem to be the foundation for the females emerging more active, dominant and determined; such as the women in the present study...The males are shown as debilitated to assume the roles and characteristics that the traditional gender symbolism assigns to them" (p. 215).

These changing circumstances with respect to sex roles my therefore set the dissimilar social contexts in which individual differences in patriarchal values may have more influence upon intersexual conflict in Costa Rica than in Mexico. As with $\mathrm{COH}$, differing social contexts might establish sufficiently dissimilar cultural and ecological scenarios within which varying individual dispositions are either differentially facilitated or suppressed.

Within biological systems, the various levels of analysis can be thought of as members of a constitutive hierarchy, as described by Ernst Mayr (1982):

In such a hierarchy the members of a lower level, let us say tissues, are combined into new units (organs) that have unitary functions and emergent properties... At each level there are different problems, different questions to be asked, and different theories to be formulated. Each of these levels has given rise to a separate branch of biology; molecules to molecular biology, cells to cytology, tissues to histology, and so forth, up to biogeography and the study of ecosystems. (Mayr, 1982, p. 65)

Journal of Social, Evolutionary, and Cultural Psychology - ISSN 1933-5377 - volume 3 (1) 2009. 
Mayr uses the concept of emergence here in the "weak" (non-mystical) sense in that the properties of a system are ultimately reducible to the products of the interactions among its constituents, as opposed to the "strong" sense in which the properties of an integrated whole are not reducible to the synergistic effects of its component parts (Laughlin, 2005). Social ecologies ("cultures") can therefore be envisioned as part of this constitutive hierarchy. Thus, early sociobiologists as well as later evolutionary psychologists (e.g., Lumsden \& Wilson, 1981; Tooby \& Cosmides, 1992) were correct to point out that individual psychological traits may have profound and pervasive influences upon higher-order cultural patterns of social behavior. Through bottom-up causal interactions, the material properties of a lower level of organization can constrain those of the levels above it. However, anthropologists (e.g., Irons, 1998; Richerson \& Boyd, 1998, 1999, 2001a, 2001b) are also correct to counter that higher-order social and cultural environments may also constrain the adaptive functioning of individual behavior. This was also explicitly acknowledged by Lumsden and Wilson (1981) in their theory of geneculture coevolution. Through top-down causal interactions, the emergent properties of a higher level of organization can constrain the behavior of the levels below it. Constraint, then, may be a mutual and reciprocal process among these hierarchically organized levels (Figueredo et al., 2007).

The present study therefore repeats all of the measures and procedures, as well as the specific statistical analyses, performed upon the Hermosillo, Sonora, sample (Figueredo et al., 2001), upon an independent sample from San José, Costa Rica. We hypothesized that although the same individual-level risk factors for spousal abuse (partner mate quality and socioeconomic status; Figueredo \& McCloskey, 1993; Figueredo et al., 2001) would be cross-culturally replicated, the familial- and societallevel risk and protective factors for spousal abuse (the cumulative interactions of the specified family structure parameters; Figueredo et al., 2001) would not be replicated within the context of a low-COH society. Because the cumulative interactions were multiplicative in nature, low- $\mathrm{COH}$ should nullify the joint and synergistic effects of the four essential components.

One completely novel aspect of this present study is that we assessed both spousal abuse of women by men and spousal abuse of men by women, as reported both by male and by female respondents. This provided some additional opportunities for testing hypotheses regarding the various possible causes of domestic violence.

\section{Participants}

\section{Methods}

The study was based on the interviews of 261 women and 138 men. All participants were native Costa Ricans and were interviewed in the San José metropolitan area, in the Central Valley of Costa Rica between 2002 and 2005. All respondents were screened for having been involved in committed sexual relationships during the past year, but not relationships with each other. This last precaution was taken to avoid any harm that might come to one partner if it were detected that he or she was reporting to us on the other.

Journal of Social, Evolutionary, and Cultural Psychology - ISSN 1933-5377 - volume 3 (1) 2009. 
As in the previous Hermosillo, Sonora, study, the participants were recruited as two independent subsamples to represent two documented risk factors for spousal abuse: (1) lower social class, and (2) family dysfunction.

Social Class Subsamples. The lower-class subsamples were recruited from neighborhoods in the San José metropolitan area, based on socioeconomic information from census tract data and maps. These included the following communities: Tirrases de Curridabat, Guadalupe de Goicoechea, Calle Blancos de Goicoechea, San Juan de Dios de Desamparados, San Antonio de Desamparados, Hatillo 8, San Sebastián, Purral, Aserrí, León XIII and Cristo Rey. These subsamples were considered at increased risk for spousal abuse because of the documented role of the relative socioeconomic status and employment stability of the partners on domestic violence (Figueredo \& McCloskey, 1993).

Family Dysfunction Subsamples. Another set of subsamples was constructed from the parents of children who had been identified at 20 local schools as having emotional problems. These subsamples was also considered to be at high risk because of the known multiple correlation between spousal abuse, child abuse, and various forms of child psychopathology, notably conduct disorders (McCloskey, Figueredo, \& Koss, 1995). The names of the schools from which these families were recruited have been withheld for purposes of confidentiality.

As in the previous Hermosillo, Sonora, study, these two recruiting sources were selected to oversample informative cases of spousal abuse, as is necessary for low incidence events. The U.S. 1995 National Violence Against Women Survey of some 8000 women (Tjaden \& Thoennes, 1998), found that when asked to enumerate occurrences during "the last 12 months", the percentage of women reporting sexual assault was $0.3 \%$, the percentage of women reporting physical abuse was $1.9 \%$, and the percentage of women reporting either physical or sexual assault was $2.1 \%$. For a sample numbering about 400 respondents, as in the present study, if the same incidence of assaults prevailed then these percentages would be expected to yield at most 4 or 5 informative cases, which would be clearly inadequate to support testing any predictive hypotheses.

Nevertheless, the current oversampling plan was designed to avoid the possible biases inherent in criterion sampling, or "Conditioning on the Consequence" (Dawes, 1988, 1993, 1994), which in this case would entail sampling known cases of spousal abuse, as by sampling from battered women's shelters. Instead, oversampling may be more safely done by predictor sampling, or "Conditioning on the Antecedents", which in this case entails sampling based on known or suspected risk factors of spousal abuse rather than definite knowledge of the occurrence of spousal abuse itself. For example, in the specific case of some of our own previous research (e.g., Figueredo \& McCloskey, 1993), sampling battered women exclusively from shelters might have produced systematic biases, such as oversampling women with inadequate family support, which might have seriously compromised the validity of the present study.

Because there is no single sampling scheme that is completely free of sampling bias, due to the different "local molar conditions" (Campbell, 1986) of each sampling situation, we hoped to instead avail ourselves of the "heterogeneity of irrelevancies" (Cook, 1993; Figueredo, 1993) that might be presumed to exist between these different

Journal of Social, Evolutionary, and Cultural Psychology - ISSN 1933-5377 - volume 3 (1) 2009. 
subsamples. Based on the principle of using heterogeneous methods to offset each others' intrinsic biases (Campbell \& Fiske, 1959; Cook \& Campbell, 1979), the idea was to sample on multiple, theoretically-specified antecedents and construct a composite and hopefully heterogeneous sample based on different risk factors, rather than on any single one. For example, our Family Dysfunction subsamples were not necessarily of lower Social Class, and vice versa. This procedure, which might be called "Conditioning on Multiple Antecedents", was intended to somewhat mitigate the limited external validity often produced by predictor sampling and can only be expected to work if the subsamples are combined into a single composite sample, as was done in the previous Hermosillo, Sonora, study. Thus, to construct a maximally informative sample with predictor sampling, one loses the direct generalizability of one's parameter estimates in the attempt to describe the underlying causal processes that might be at work in the general population without addressing issues of relative prevalence. For example, when a behavioral geneticist compares a sample of $M Z$ to $D Z$ twins, he is constructing what has been called a "genetically informative sample"; these focused comparisons reveal the processes of genetic transmission that are presumably common to all humans, whether or not they are twins. However, such a design does not specifically address the relative prevalence of either type of twinning, and, if misused in that way, would produce vastly distorted estimates of prevalence as compared with the general population. Therefore, if properly used and interpreted, it is often beneficial to intentionally construct an unrepresentative sample.

\section{Procedures}

Respondents were initially contacted either in person at their own home or over the phone in the case of some referrals from schools. All respondents were informed in advance that they would be participating in a study on extended family structure and its relationship to family conflict. They were also informed that they could choose to stop the interview at any time or to refuse to answer any individual question without discontinuing the interview. Most of the interviews were conducted in the respondents' own homes by a native Costa Rican Spanish speaker and generally took anywhere from one to two hours. Female interviewers always interviewed female study participants and male interviewers always interviewed male study participant. We acceded to all requests for alternative times in light of the possible safety issues for the protection of the study participants. Interview questions pertained mostly to the respondents' family structure, family support, and family conflict, including their possible experience of domestic violence. In this present study, we also measured plausible sources of cultural and ideological mechanisms (Culture of Honor and Patriarchal Beliefs), major dimensions of psychopathology (Anxiety and Depression) and substance abuse (Alcohol), and indicators of "General Theory of Crime" criminality (Permissive and Risk-taking Attitudes), to test the relevant dimensions as alternative hypotheses regarding the potential causes of the observed levels of domestic violence.

This research project received all appropriate Institutional Review Board (IRB) reviews and approvals in terms of participant confidentiality, safety, and potential risks. All persons interviewed were required sign consent forms to participate; there was no penalty either for refusing to answer any particular question or for complete withdrawal

Journal of Social, Evolutionary, and Cultural Psychology - ISSN 1933-5377 - volume 3 (1) 2009. 
from the study; no names were included on the questionnaire; data will be deleted by a shredded system after keeping for five years in a locked drawer; and electronic data using anonymous identification codes will be stored for future study.

\section{Measures}

While the interview protocol included numerous measures, those reported in this paper primarily concerned the types and amounts of aggression between individuals within the family and the demographic and socioeconomic profiles of individuals within the family. All assessment instruments had been previously used in Hermosillo, Sonora (Figueredo, Corral-Verdugo, Frías-Armenta, et al., 2001), and were originally translated by native Spanish speakers who were experienced in such translation. The following are brief descriptions of the specific measures used. Some of these measures were published scales, used in their entirety, whereas others were carved-out scales composed of selected subsets of items from published scales. Other scales were author-constructed, by either adapting selected items from a variety of existing measures or generating new ones by following very closely the published theories of measurement cited. A complete listing of the items used in the various carved-out and author-constructed scales was provided in the appendix of Figueredo et al. (2001), but not for any published scales that were used without significant modification. Some of the items originally used in the Hermosillo, Sonora, study were dropped in the present analysis due to differential item functioning across cultural groups, as indicated by their effects (e.g., item-total correlations) upon internal consistencies of the various scales. Certain items were also modified to conform to local idiomatic expressions used preferentially in Costa Rica as opposed to Mexico. Neither of these steps had any appreciable impact upon the functioning of the scales. Internal consistencies (Cronbach's alpha) for each of these scales, whether used directly, carved-out, or author-constructed, are provided in the section on statistical analyses.

Spousal Abuse. We administered our previously-used version of the Conflict Tactics Scales (Straus, 1979, 1990b) to each respondent (Figueredo, Corral-Verdugo, Frías-Armenta, et al., 2001). This included several additional questions about rape or sexual abuse within the relationship (e.g., "How often has he forced you to have sexual intercourse against your will, when you didn't want to?"). We adapted this same set of items to obtain self-reports of both male and female perpetration of spousal abuse as well as male and female victimization by their partners.

Sexual Relationship Dynamics. To better understand the dynamics of the respondents' primary sexual relationships, we asked them questions relating to the general quality of their relationship with their current partner. To obtain an estimate of the mate value that they attributed to their current sexual partners, we used the Mate Value Inventory (MVI; Kirsner, Figueredo, \& Jacobs, 2003). The MVI is a 22-item selfreport scale that asks participants to rate either themselves or others on 17 traits theoretically deemed important in mate attraction (e.g., attractiveness, financial security, emotional stability), with five additional distraction items (jealous, aggressive, controlling, possessive, manipulative) not included in the analysis. This scale is based on documented parameters of mate quality for both sexes (e.g., Buss, 1989, 1994).

Family Demographics. Our demographic questionnaire assessed such items as the respondents' and their partners' current employment status, their separate incomes

Journal of Social, Evolutionary, and Cultural Psychology - ISSN 1933-5377 - volume 3 (1) 2009. 
from work and other sources, their perceived social class, years of education completed, and their current occupations. We also asked them how many children they had in the household and if these children belonged to either one or both partners or were either stepchildren or adopted. In addition, we asked them to count for us how many genetic relatives they had both inside and outside the city of San José, specifying that any "inlaws" or relations by marriage be excluded from this tally. This was done by enumerating each type of relative by category (e.g., uncles, aunts, nephews, nieces), and we accepted reasonable approximations where exact numbers were not available (which occurred in some of the larger families). We then asked detailed questions on the socioeconomic status of immediate blood kin (e.g., father, mother, sisters, brothers) with the highest coefficient of relationship $(r . g=0.50)$. This was used as a proxy for the general socioeconomic status of the entire extended family because it was not deemed reasonable to expect any individual to remember that level of detail for all his or her genetic relatives. Finally, we asked a published battery of 17 questions regarding the amounts and types of both emotional and instrumental social support typically received by each respondent from his or her genetic relatives (Barrera, Sandler, \& Ramsay, 1981).

Cognitive and Ideological Factors. To assess the self-reported adherence to patriarchal values of the respondent and that of the respondent's partner, and to put this construct into a form more amenable to empirical testing, we constructed a patriarchy scale that reflected beliefs regarding male hegemony in marital relationships that are commonly held in mainstream Mexican culture ( $c f$., Diaz-Guerrero, 1975).

We also included an additional set of items inspired by Nisbett \& Cohen's (1996) "Culture of Honor" theory to assess adherence to an ideology of revenge that would serve as a justification for the instrumental use of violence within both the intrafamilial and interfamilial spheres of social life. These items consisted of hypothetical vignettes for which the respondent is asked to either approve or disapprove the actions of a hypothetical protagonist involved in either a negative or positive social exchange. Wherever we refer to a respondent's personal culture or code of honor throughout the present paper, we use it to denote the specific ideology assessed by the respondent's score on this "revenge" factor, a psychometric construct which we believe to be generally consistent with the original ethnographic descriptions (e.g., Nisbett \& Cohen, 1996). Specifically, we used the Revenge scale documented and cross-culturally validated in Figueredo, Tal, McNeill, \& Guillén (2004).

Measures of general anxiety and depression were obtained by "carving out" shortened versions of the Hamilton (1959) Anxiety Scale and the Hamilton $(1980,1985)$ Depression Scale, selecting 11 items and 14 items, respectively, based on sampling the broader domain of anxious and depressive symptoms. These were included to control for any spurious "negativity bias" effects on the self-reports of both partner mate quality and spousal abuse. The habitual alcohol use of both the respondent and the respondent's current partner were assessed by asking several questions on the frequency and quantity on "equivalent" drinks typically imbibed on weekdays and on weekends. These items were originally derived and then adapted from the parent's version of the Diagnostic Inventory for Children and Adolescents ( $c f$. , Reich \& Herjanic, 1989; Reich, Earls, Frankel, \& Shayka, 1993).

Journal of Social, Evolutionary, and Cultural Psychology - ISSN 1933-5377 - volume 3 (1) 2009. 
General criminality was assessed by asking the respondent to endorse or reject views reflecting attitudes that were either permissive towards criminality, impulsive, or risk-prone (Gottfredson \& Hirschi, 1990). A total of 16 items of this type were drawn from published research applying the "General Theory of Crime" perspective. Because this measure represents one particular view of the nature of criminality, we will use General Theory of Crime criminality throughout this paper, in spite of its possible awkwardness, to emphasize the theory-bounded specificity of this construct.

\section{Statistical Analyses}

Scale Construction. The statistical software package used for all of these analyses was $S A S$ 8.2 (SAS Institute, 1999). First, we theoretically assigned the items to hypothesized factor scales. We computed unit-weighted common factor scores for all the factor scales in SAS (PROC STANDARD and DATA), using the means of the standardized item scores for all non-missing items on each subscale (Figueredo et al., 2000; McKnight et al., 2007). Theoretically-specified interactions between scales were also computed in $S A S$ by the creation of multiplicative terms (Cohen \& Cohen, 1983). Although the main effects of the various interaction terms were included in the prediction equations, all possible interactions between them were not generated and tested, but only those which were predicted by theory were constructed and included in the multiple regression model. We also computed both the Cronbach's alphas and the covariance matrices of the factor scales in SAS (PROC CORR). The internal consistencies of each of these factor scales are presented in Table 1. Some of these scales had somewhat lower alphas due to a low number of items, but had acceptable item-factor correlations. The single-item scales, calculated local kin density indices, and interaction terms which were included in the model, but for which Cronbach's alphas are not applicable, are presented in Table 2.

Table 1. Interitem Consistencies (Cronbach's Alpha) of Unit-Weighted Factor Scales.

\begin{tabular}{|c|c|c|c|}
\hline$C O D E$ & WOMEN & $M E N$ & DESCRIPTION OF MEASURE \\
\hline $\mid \overline{M-S P O U S A L}$ & 0.96 & 0.91 & Spousal Abuse by Men (Verbal, Physical, Escalated, Sexual) \\
\hline F-SPOUSAL & 0.90 & 0.89 & Spousal Abuse by Women (Verbal, Physical, Escalated, Sexual) \\
\hline$P-M Q$ & 0.83 & 0.83 & |Partner Mate Quality (“Sex”) \\
\hline$P-S E S$ & 0.77 & 0.76 & Partner Socioeconomic Status ("Money") \\
\hline S-PATR & 0.68 & 0.77 & Self Patriarchy Scale \\
\hline$P-P A T R$ & 0.83 & 0.76 & Partner Patriarchy Scale \\
\hline$S-H O N R$ & 0.81 & 0.96 & Self Honor Scale ("Revenge") \\
\hline$S-A N X I$ & 0.88 & 0.89 & Self Anxiety Scale (Hamilton) \\
\hline$S-D E P R$ & 0.86 & 0.88 & Self Depression Scale (Hamilton) \\
\hline$S$ S-ETOH & 0.74 & 0.69 & Self Alcohol Use (Composite) \\
\hline$P-E T O H$ & 0.78 & 0.70 & Partner Alcohol Use (Composite) \\
\hline$S-C R I M$ & 0.62 & 0.51 & Self GTC Criminality (Permissive and Risky Attitudes) \\
\hline$K-S U P P$ & 0.86 & 0.90 & Kin Social Support (Emotional, Instrumental) \\
\hline$K-S E S$ & 0.93 & 0.94 & Kin Socioeconomic Status (r.g $=.50)$ \\
\hline
\end{tabular}

Journal of Social, Evolutionary, and Cultural Psychology - ISSN 1933-5377 - volume 3 (1) 2009. 
Table 2. Single-Item Scales, Calculated Local Kin Density Indices, and Interaction Terms.

\begin{tabular}{||l|l||}
\hline$C O D E$ & DESCRIPTION OF MEASURE \\
\hline \hline$S-A G E$ & Self Age (Years) \\
\hline$P-A G E$ & Partner Age (Years) \\
\hline$M K-D E N S$ & Local Male Kin Density (San José) \\
\hline$M K-S U P P$ & Local Male Kin Density * Kin Support \\
\hline$M K-P O W R$ & Local Male Kin Density * Kin Support * Kin Status \\
\hline$M K-P R O T$ & Local Male Kin Density * Kin Support * Kin Status * Self Honor \\
\hline$F K-D E N S$ & Local Female Kin Density (San José) \\
\hline$F K-S U P P$ & Local Female Kin Density * Kin Support \\
\hline$F K-P O W R$ & Local Female Kin Density * Kin Support * Kin Status \\
\hline$F K-P R O T$ & Local Female Kin Density * Kin Support * Kin Status * Self Honor \\
\hline
\end{tabular}

Because it was not possible to separately estimate the direct effects of both selfreported Anxiety $(S-A N X I)$ and Depression $(S-D E P R)$ in the same regression models due to their high collinearity, these two measures were combined into a single composite scale $(S-A N X D E P)$ which was used to control for the hypothesized "negativity bias". This aggregation was done by calculating the mean of the non-missing values of their standardized scores, as explained above.

The local kin densities of male and female relatives of each respondent were computed by assigning a coefficient of relationship ( $r . g$ ) to each category of genetic relative enumerated, assuming normal diploid sexual reproduction and no significant inbreeding between close relatives. Each coefficient of relationship was multiplied by the number of individuals reported in each category and these products were then summed for each gender. A simple algorithm for this procedure was programmed in $S A S$ (DATA). Thus, these indices represented sums of the number of relatives of each type, weighted by their genetic coefficients of relatedness to the respondent, and were essentially equivalent to measures of the local spatial density of the gene replicates of the respondent. These indices were then used in combination with various lower-order factor scales to compute multiplicative terms representing multiple-scale interactions, as explained above.

Multiple Regression Models. We entered all these factor scales, computed indices, and theoretically-specified interactions as predictors in two multiple regression models, using SAS (PROC REG). As specified above in the description of the oversampling design, all social class and family dysfunction subsamples were pooled within each sex of respondent, but separate regression models were constructed for the independent samples of women and men. As in the previous Hermosillo, Sonora, study, the social class and family dysfunction subsamples were too small to support separate analyses and would also have individually suffered from the restriction of range within each group (cf., Cohen \& Cohen, 1983).

We first modeled male perpetration of spousal abuse upon female victims, as reported by the independent samples of both men and women. We then modeled female perpetration of spousal abuse upon male victims. However, because the latter has been

Journal of Social, Evolutionary, and Cultural Psychology - ISSN 1933-5377 - volume 3 (1) 2009. 
characterized as more typically self-defensive in nature and initiated by male aggression (cf., Daly \& Wilson, 1988; White, Smith, Koss, Figueredo, 2000), we incorporated male perpetration as the first predictor in this second set of models to statistically control for any possible indirect effects of the hypothesized predictors of male aggression in triggering reciprocal female aggression. Any remaining incremental effects can therefore be interpreted as unique effects of the model predictors directly upon female aggression that are not mediated by their possible effects in promoting male initiation of the violence (cf., Figueredo \& Gorsuch, 2007).

\section{Results}

\section{Spousal Abuse of Women by Men}

Table 3 presents the results of the multiple regression models for the spousal abuse of women by men for each sex of respondent. The statistics tabulated are the ordinary least squares $(O L S)$ standardized regression weights $(\beta$-weights), with their associated t-tests and probabilities under the null hypothesis $(\beta=0)$, all listed separately by column for women and for men. The coefficients of determination (squared multiple correlations) for the spousal abuse of women by men factor were quite high in both samples $\left(R^{2}=.51\right.$ in the female sample and $R^{2}=.58$ in the male sample), indicating that the greater proportion of the observed variance in reported spousal abuse were accounted for by the specified model predictors.

Table 3. Multiple Regressions for Predictors of Spousal Abuse (Men Abusing Women).

\begin{tabular}{|c|c|c|c|c|c|c|}
\hline \multirow{2}{*}{\begin{tabular}{|l|} 
M-SPOUSAL \\
Predictor \\
\end{tabular}} & \multicolumn{3}{|c|}{ "WOMEN (VICTIMIZATION) } & \multicolumn{3}{|c|}{ "MEN (PERPETRATION) } \\
\hline & $\beta$-weight & $t$-test & $p(\beta>0)$ & $\beta$-weight & $t$-test & $p(\beta>0)$ \\
\hline$P-M Q$ & -0.16 & -3.03 & 0.003 & -0.31 & -4.05 & 0.000 \\
\hline P-SES & 0.13 & 2.03 & 0.043 & 0.07 & 0.82 & 0.412 \\
\hline$S-A G E$ & -0.05 & -0.65 & 0.517 & -0.03 & -0.21 & 0.834 \\
\hline$P-A G E$ & 0.00 & -0.01 & 0.989 & -0.13 & -1.03 & 0.306 \\
\hline$S-P A T R$ & -0.33 & -5.56 & 0.000 & 0.38 & 2.44 & 0.016 \\
\hline$P-P A T R$ & 0.59 & 8.81 & 0.000 & -0.35 & -2.32 & 0.022 \\
\hline S-HONR & 0.06 & 1.13 & 0.259 & -0.03 & -0.43 & 0.667 \\
\hline$S-A N X D E P$ & 0.21 & 4.36 & 0.000 & 0.13 & 1.86 & 0.066 \\
\hline$S-E T O H$ & -0.04 & -0.87 & 0.383 & 0.20 & 2.55 & \begin{tabular}{|l|}
0.012 \\
\end{tabular} \\
\hline P-ETOH & \begin{tabular}{|l|}
0.16 \\
\end{tabular} & 3.18 & 0.002 & 0.27 & 3.78 & \begin{tabular}{|l|}
0.000 \\
\end{tabular} \\
\hline S-CRIM & \begin{tabular}{|l|}
-0.09 \\
\end{tabular} & -1.71 & 0.089 & 0.31 & 4.31 & \begin{tabular}{|l|}
0.000 \\
\end{tabular} \\
\hline$K-S U P P$ & 0.07 & 1.43 & 0.153 & \begin{tabular}{|l|}
-0.02 \\
\end{tabular} & -0.31 & 0.757 \\
\hline$K-S E S$ & \begin{tabular}{|l|}
-0.06 \\
\end{tabular} & -0.92 & 0.357 & 0.05 & 0.60 & 0.549 \\
\hline$M K-D E N S$ & \begin{tabular}{|l|}
0.05 \\
\end{tabular} & 0.70 & \begin{tabular}{|l|}
0.482 \\
\end{tabular} & \begin{tabular}{|l|}
-0.02 \\
\end{tabular} & -0.15 & 0.884 \\
\hline$M K-S U P P$ & 0.08 & 1.05 & 0.294 & 0.08 & 0.55 & 0.582 \\
\hline MK-POWR & \begin{tabular}{|l|}
-0.04 \\
\end{tabular} & -0.46 & 0.648 & \begin{tabular}{|l|}
-0.02 \\
\end{tabular} & -0.16 & 0.874 \\
\hline MK-PROT & -0.04 & -0.46 & 0.644 & -0.17 & -1.28 & 0.203 \\
\hline$F K-D E N S$ & \begin{tabular}{|l|}
-0.10 \\
\end{tabular} & -1.49 & 0.137 & 0.14 & 1.11 & 0.270 \\
\hline$F K-S U P P$ & \begin{tabular}{|l|}
-0.13 \\
\end{tabular} & -1.65 & 0.100 & -0.03 & -0.22 & 0.829 \\
\hline FK-POWR & 0.04 & 0.41 & 0.682 & $\mid$\begin{tabular}{|l|}
-0.09 \\
\end{tabular} & -0.53 & 0.600 \\
\hline
\end{tabular}

Journal of Social, Evolutionary, and Cultural Psychology - ISSN 1933-5377 - volume 3 (1) 2009. 


\begin{tabular}{||l||l|l|l||l|l|l||}
\hline FK-PROT & 0.09 & 1.03 & 0.306 & 0.17 & 1.01 & 0.314 \\
\hline
\end{tabular}

As in the Hermosillo, Sonora, study, several cognitive and ideological factors were included in the model as multiple alternative hypotheses to control for any spurious components of the correlations previously found (Figueredo \& McCloskey, 1993) between the respondents' self-reports of partner socioeconomic status, partner mate quality, and partner-perpetrated spousal abuse. These factors included: $(S-P A T R)$ selfreported patriarchy, $(P-P A T R)$ reported partner patriarchy, $(S-H O N R)$ assessed personal honor, $(S-D E P R)$ self-reported depression, $(S-E T O H)$ self-reported alcohol use, $(P-$ $E T O H)$ reported partner alcohol use, and $(S-C R I M)$ self-reported GTC criminality. The effects of the Partner mate quality $(P-M Q)$ and partner socioeconomic status $(P-S E S)$ factors on reported spousal abuse were therefore determined when controlling for these otherwise confounding influences. The main effects and specified two-way, three-way, and four-way interactions of the respondent's family structure parameters on reported spousal abuse were then estimated to evaluate the predictions of the family deterrence hypothesis.

The first set of influences on spousal abuse tested were those found previously and labeled "Sex" and "Money" (Figueredo \& McCloskey, 1993). Perceived partner mate quality $(P-M Q /$ "Sex") directly and substantially decreased both the self-reported spousal abuse of women and the self-reported perpetration of spousal abuse by men. This first finding constituted a qualitative cross-cultural confirmation of the previous results obtained in both a Tucson, Arizona, sample (Figueredo \& McCloskey, 1993) and the Hermosillo, Sonora, sample (Figueredo et al., 2001). Partner socioeconomic status $(P$ $S E S /$ "Money") also directly influenced the self-reported spousal abuse of women, but not the self-reported perpetration of spousal abuse by men. However, the direction of the effect on the self-reported spousal abuse of women was opposite to the one expected, being positive instead of negative.

The second set of influences tested relate to the hypothesized cognitive and ideological influences on spousal abuse. The effects of age were included in the regression model to control statistically for any greater adherence to more traditional beliefs by older respondents or their older partners. However, neither respondent age $(S$ $A G E)$ nor partner age $(P-A G E)$ directly influenced either the self-reported perpetration of spousal abuse by the men or the self-reported spousal abuse of the women. This was consistent with the Hermosillo, Sonora, results, although it was not consistent with some previous research that found that younger women, having higher reproductive value, were at higher risk for spousal abuse (Daly \& Wilson, 1996; Figueredo \& McCloskey, 1993).

However, contrary to the Mexican results, both the self-reported patriarchal beliefs of women and the self-reported patriarchal beliefs of men (S-PATR) directly influenced the self-reported spousal abuse of women and the self-reported perpetration of spousal abuse by men, respectively, in the expected equal and opposite directions. Less patriarchal women experienced more self-reported spousal abuse; more patriarchal men perpetrated more self-reported spousal abuse. Moreover, the patriarchal beliefs attributed to their partner $(P-P A T R)$ by either men or women also directly influenced self-reported spousal abuse. Women who rated their spouses as more patriarchal experienced more

Journal of Social, Evolutionary, and Cultural Psychology - ISSN 1933-5377 - volume 3 (1) 2009. 
spousal abuse, men who rated their spouses as less patriarchal perpetrated more abuse. The effects of these latter spousal reports are consistent in direction with those of the selfreported patriarchal beliefs and thus help to validate the reports across respondents. Nevertheless, neither the assessed personal code of honor of men nor that of women $(S$ $H O N R$ ) directly increased either the self-reported perpetration of spousal abuse by men or the self-reported spousal abuse of women.

The self-reported anxiety and depression $(S-A N X D E P)$ of women directly increased the self-reported spousal abuse experienced by women, but that of men did not directly increase the perpetration of spousal abuse by men. In contrast, the self-reported alcohol use of men $(S-E T O H)$ directly increased the self-reported perpetration of spousal abuse by men, but that of women did not influence the self-reported spousal abuse experienced by women. Nevertheless, the partner alcohol use (P-ETOH) reported by the respondents, whether they were men or women, directly increased both the self-reported perpetration of spousal abuse by men and the self-reported spousal abuse of women. This indicates at least a partial contradiction between the partner reports with regards to the effects of alcohol use by women. Finally, the self-reported GTC criminality (S-CRIM) directly increased the self-reported perpetration of spousal abuse by men, but that of women did not significantly influence the self-reported spousal abuse experienced by women.

The third set of influences tested relate to the role of the extended family as a social regulator of spousal abuse, as specifically predicted from the family deterrence hypothesis. Here we find the single most striking difference between the Costa Rican and the Mexican results. Absolutely none of the main effects or complex interactions of local density of male kin ( $M K-D E N S, M K-S U P P, M K-P O W R$, and $M K-P R O T)$ that were found to be significant predictors of spousal abuse in the Hermosillo study, simultaneously protecting women from spousal abuse but empowering men to perpetrate it, were found to be statistically significant in the San José sample. However, as explained above, this was precisely what was theoretically predicted.

Also, as in the Hermosillo study, none of the main effects or specified interactions of the local density of female kin (FK-DENS, FK-SUPP, FK-POWR, and $F K$-PROT), were found statistically significant for the self-reported spousal abuse of women. Furthermore, none of these same interactions were found to be significant predictors of the self-reported perpetration of spousal abuse by men. In Hermosillo, but not in San José, the main effect of the local density of female kin (FK-DENS) and that of the four-way interaction $(F K-P R O T)$ of local kin density of female kin with family support, family socioeconomic status, and personal honor was found to be significant and negative for the self-reported perpetration of spousal abuse by men. The female relatives of the men in Hermosillo somehow saw it in their interests to partially moderate the sexually coercive tactics of their male family members, but this effect did not occur in San José.

\section{Spousal Abuse of Men by Women}

Table 4 presents the results of the multiple regression models for the spousal abuse of men by women for each sex of respondent. It has been widely theorized (e.g., Daly \& Wilson, 1988; White et al., 2000), from both feminist and evolutionary

Journal of Social, Evolutionary, and Cultural Psychology - ISSN 1933-5377 - volume 3 (1) 2009. 
psychological perspectives, that women's spousal abuse of men is largely self-defensive in nature. To statistically control for this likely, but not necessarily exhaustive, effect, we entered male spousal abuse of women as the first predictor in our multiple regression models for the spousal abuse of men by women. Thus, any additional significant effects may be considered to be direct effects of the other predictors that are not mediated by the spousal abuse of women by men. Therefore, all effects described below should be interpreted as such, even if the qualification is not made explicit in each sentence.

As above, the statistics tabulated are the ordinary least squares $(O L S)$ standardized regression weights ( $\beta$-weights), with their associated t-tests and probabilities under the null hypothesis $(\beta=0)$, all listed separately by column for women and for men. The coefficients of determination (squared multiple correlations) for the spousal abuse of men by women factors were quite high in both samples $\left(R^{2}=.47\right.$ in the female sample and $R^{2}=.71$ in the male sample), indicating that the greater proportion of the observed variance in reported spousal abuse were accounted for by the specified model predictors.

Table 4. Multiple Regressions for Predictors of Spousal Abuse (Women Abusing Men).

\begin{tabular}{|c|c|c|c|c|c|c|}
\hline \multirow{2}{*}{\begin{tabular}{|l|}
$F-S P O U S A L$ \\
Predictor \\
\end{tabular}} & \multicolumn{3}{|c|}{ WOMEN (PERPETRATION) } & \multicolumn{3}{|c|}{ MEN (VICTIMIZATION) } \\
\hline & $\beta$-weight & $t$-test & $p(\beta>0)$ & $\beta$-weight & $t$-test & $p(\beta>0)$ \\
\hline M-SPOUSAL & 0.54 & 8.01 & 0.000 & 0.63 & 8.18 & 0.000 \\
\hline$P-M Q$ & -0.12 & -2.14 & 0.034 & -0.14 & -2.11 & 0.037 \\
\hline$P-S E S$ & -0.04 & -0.68 & 0.498 & 0.01 & 0.12 & 0.901 \\
\hline$S-A G E$ & -0.05 & -0.62 & 0.538 & -0.13 & -1.26 & 0.211 \\
\hline$P-A G E$ & -0.06 & -0.78 & 0.436 & 0.06 & 0.60 & 0.550 \\
\hline S-PATR & 0.02 & 0.27 & 0.789 & 0.25 & 1.92 & 0.058 \\
\hline$P-P A T R$ & -0.17 & -2.13 & 0.035 & -0.20 & -1.55 & 0.123 \\
\hline$S-H O N R$ & -0.05 & -0.93 & 0.351 & 0.09 & 1.59 & 0.115 \\
\hline$S-A N X D E P$ & 0.21 & 4.09 & 0.000 & 0.01 & 0.17 & 0.866 \\
\hline S-ETOH & 0.07 & 1.44 & 0.151 & -0.04 & -0.61 & 0.541 \\
\hline P-ETOH & 0.12 & 2.22 & 0.028 & 0.21 & 3.33 & 0.001 \\
\hline S-CRIM & 0.05 & 0.98 & 0.327 & -0.04 & -0.56 & 0.579 \\
\hline$K-S U P P$ & 0.00 & 0.04 & 0.969 & 0.05 & 0.81 & 0.419 \\
\hline$K-S E S$ & 0.04 & 0.56 & 0.579 & -0.02 & -0.28 & 0.782 \\
\hline$M K-D E N S$ & 0.05 & 0.72 & 0.474 & -0.21 & -1.89 & 0.061 \\
\hline$M K-S U P P$ & -0.05 & -0.63 & 0.526 & -0.03 & -0.24 & 0.809 \\
\hline$M K-P O W R$ & 0.16 & 1.66 & 0.098 & -0.01 & -0.08 & 0.939 \\
\hline MK-PROT & -0.11 & -1.20 & 0.230 & 0.09 & 0.82 & 0.416 \\
\hline$F K-D E N S$ & -0.03 & -0.38 & 0.704 & 0.19 & 1.74 & 0.085 \\
\hline$F K-S U P P$ & 0.07 & 0.84 & 0.403 & 0.10 & 0.85 & 0.398 \\
\hline FK-POWR & -0.16 & -1.64 & 0.102 & 0.07 & 0.47 & 0.639 \\
\hline$F K-P R O T$ & 0.06 & 0.63 & 0.527 & -0.16 & -1.11 & 0.271 \\
\hline
\end{tabular}

Journal of Social, Evolutionary, and Cultural Psychology - ISSN 1933-5377 - volume 3 (1) 2009. 
As before, the first set of influences on spousal abuse tested were those found previously and labeled "Sex" and "Money" (Figueredo \& McCloskey, 1993). As with spousal abuse of women by men, perceived partner mate quality $(P-M Q /$ "Sex") directly and significantly decreased both the spousal abuse of men perpetrated by women, as selfreported by the women themselves, and the spousal abuse of men by women, as reported by the men. This indicates that not only are lower-mate-quality, Competitively Disadvantaged Males (CDMs) more subject to spousal abuse by women, independently of their own perpetration, but that Competitively Disadvantaged Females (CDFs) may be abusive over and above the degree attributable to their assortative mating with abusive partners who are likely to be CDMs, as originally suggested in Figueredo et al. (2001). Partner socioeconomic status (P-SES/“Money") did not directly influence either the spousal abuse of men perpetrated by women, as self-reported by women, or the spousal abuse experienced by men, as reported by men.

Again, the second set of influences tested relate to the hypothesized cognitive and ideological influences on spousal abuse. As before, the effects of age were included in the regression model to control statistically for any greater adherence to more traditional beliefs by older respondents or their older partners. However, neither respondent age $(S-A G E)$ nor partner age $(P-A G E)$ directly influenced either the spousal abuse of men perpetrated by women, as self-reported by women, or the spousal abuse experienced by men, as reported by men.

Furthermore, neither the self-reported patriarchal beliefs of women nor the selfreported patriarchal beliefs of men $(S-P A T R)$ directly influenced either the spousal abuse of men perpetrated by women, as self-reported by women, or the spousal abuse experienced by men, as reported by men. Nevertheless, the patriarchal beliefs attributed to their partner $(P-P A T R)$ by women directly influenced the spousal abuse of men perpetrated by women, as self-reported by women. Women who rated their spouses as less patriarchal perpetrated more self-reported spousal abuse of men. The corresponding effect of partner patriarchy was not significant for the spousal abuse experienced by men as reported by men. Neither the assessed personal code of honor of men nor that of women $(S-H O N R)$ directly influenced either the spousal abuse of men perpetrated by women, as self-reported by women, or the spousal abuse experienced by men, as reported by men.

The self-reported anxiety and depression $(S-A N X D E P)$ of women directly increased the spousal abuse of men perpetrated by women, as self-reported by women, but not the spousal abuse experienced by men, as reported by men. Neither the selfreported alcohol use of women nor the self-reported alcohol use of men $(S-E T O H)$ directly influenced either the spousal abuse of men perpetrated by women, as selfreported by women, or the spousal abuse experienced by men, as reported by men. Nevertheless, the partner alcohol use $(P-E T O H)$ reported by the respondents, whether they were men or women, directly increased both the self-reported perpetration of spousal abuse by men and the self-reported spousal abuse of women. This again indicates a contradiction between the respondent reports with regards to the effects of alcohol use by their partners. Finally, neither the self-reported GTC criminality of women nor the self-reported $G T C$ criminality of men (S-CRIM) directly influenced either the spousal

Journal of Social, Evolutionary, and Cultural Psychology - ISSN 1933-5377 - volume 3 (1) 2009. 
abuse of men perpetrated by women, as self-reported by women, or the spousal abuse experienced by men, as reported by men.

The third set of influences tested relate to the role of the extended family as a social regulator of spousal abuse, as specifically predicted from the family deterrence hypothesis. As with the findings for spousal abuse of women by men in the San José sample, none of the main effects or complex interactions of local density of male kin (MK-DENS, MK-SUPP, MK-POWR, and MK-PROT) that were found to be significant predictors of the spousal abuse of women by men in the Hermosillo study, simultaneously protecting women from spousal abuse but empowering men to perpetrate it, were found to be statistically significant in the San José sample with respect to the spousal abuse of men by women. Also, none of the main effects or specified interactions of the local density of female kin (FK-DENS, FK-SUPP, FK-POWR, and FK-PROT), were found statistically significant for spousal abuse of men, as reported by either men or women.

\section{Discussion}

Our first major objective was to cross-culturally cross-validate the common findings of both the original Tucson study (Figueredo \& McCloskey, 1993) and the subsequent Hermosillo study (Figueredo et al., 2001) with respect to the CDM theory of spousal abuse. Limiting our initial comparison to this subset of results, we see that the most theoretically important findings were indeed replicated: partner mate quality $(P$ $M Q$ ) was a significant, substantial, and negative influence on spousal abuse. We now found that this effect is common to both the spousal abuse of women by men and the spousal abuse of men by women, regardless of the sex of the respondent. $C D M$ was the acronym used to denote Competitively Disadvantaged Males, or men of low mate quality and low socioeconomic status, who were hypothesized to disproportionately utilize spousal abuse to retain and dominate their mates. As in the Hermosillo results, the San José findings indicate that a similar, though not identical, logic also extends to $C D F \mathrm{~s}$, or Competitively Disadvantaged Females. The asymmetrical sexual dynamics of this phenomenon is described in Figueredo et al. (2001).

The second major objective of this study was to test the family deterrence hypothesis in a low-COH (traditionally agricultural) society. As expected by theory, the San José, Costa Rica, sample showed no family deterrence by the women's local male kin of spousal abuse of women by men and no family facilitation by the men's local male kin of perpetration of spousal abuse of women by men, as reported by either male or female respondents. In addition, these results showed no family facilitation by the women's local male kin of spousal abuse of men by women, as reported by either male or female respondents. There is apparently no "sexual balance of power" at work in the family dynamics of intramarital conflict in San José, Costa Rica, even among individuals who might have a high personal code of honor, or ideology of revenge.

Also worthy of note is the finding that, consistently with feminist theory, the patriarchal beliefs of both men and women did significantly affect both the spousal abuse of women by men and the spousal abuse of men by women (although affecting the latter to a somewhat lesser extent). These results were not found in the Hermosillo study, perhaps because the more socially conservative Sonoran society (García et al., 2002) may

Journal of Social, Evolutionary, and Cultural Psychology - ISSN 1933-5377 - volume 3 (1) 2009. 
provide fewer occasions for marital conflicts over patriarchal values. Contrary to the specific feminist hypothesis, however, our results suggest that conflict over patriarchal values, specifically the combination of high male with low female patriarchal values, is what triggers abuse rather than the overall level of patriarchy in the society as a whole.

In addition to sociopolitical differences regarding the social consensus (or lack thereof) on patriarchal values in Hermosillo, Sonora, and San José, Costa Rica, there are great differences in the degree of inequality among the social classes between the two societies. This is potentially important because one of the essential elements of the hypothesized 4-way interactions among family structure parameters was family socioeconomic status. In a more socially egalitarian society, this component may be less relevant. Therefore, it might be premature to conclude that systematic differences in $\mathrm{COH}$ alone were uniquely responsible for the observed differences between the cross-cultural replications. There might have been more restriction of range in socioeconomic status of study participants in the Costa Rican sample than in the Mexican sample.

Virtually any cross-cultural study is almost inevitably subject to numerous confounds. This is because it is almost never possible to find two or more human societies that differ in nothing but the one single dimension of interest. Usually, human societies differ in various ways. We therefore acknowledge that it is not possible to completely control for all possible confounding variables without testing these hypotheses in many other related societies, which is something much easier said than done. In our studies, for example, we applied statistical control of some of these sociocultural differences other than in $\mathrm{COH}$ (e.g., patriarchal beliefs, socioeconomic status) by including all these predictors within the same multiple regressions rather than by attempting to quasi-experimentally sample societies that were equivalent on all dimensions but $\mathrm{COH}$. Plans are currently underway to replicate these findings in México City, DF, to address at least some of the alternative hypotheses, but completion of this task might still be years away. For now, we believe that we may reasonably consider these results to constitute at least tentative support for our theoretical predictions.

\section{Received 9/17/08, Revision received 1/15/08, Accepted 1/16/08}

\section{References}

Alvarez, A.T. (2007). Un estudio transgeneracional acerca de la construcción de las identidades femeninas y masculinas en tres tipos de familias. Unpublished doctoral dissertation, Universidad de Costa Rica, Programa Latinoamericano de Doctorado en Educación.

Barrera, M., Jr., Sandler, I.N., \& Ramsay, T.B. (1981). Preliminary development of a scale of social support: Studies on college students. American Journal of Community Psychology, 9(4), 435-447.

Buss, D.M. (1989). Sex differences in human mate preferences: Evolutionary hypotheses tested in 37 cultures. Behavioral and Brain Sciences, 12, 1-49.

Buss, D. (1994). The Evolution of Desire: Strategies of Human Mating. New York: Basic Books.

Journal of Social, Evolutionary, and Cultural Psychology - ISSN 1933-5377 - volume 3 (1) 2009. 
Campbell, D.T. (1986). Relabeling internal and external validity for applied social scientists. In Trochim, W.M.K., (Ed.), Advances in quasi-experimental design and analysis. New Directions for Program Evaluation, No. 31. San Francisco: Jossey-Bass, 67-77.

Campbell, D.T., \& Fiske, D.W. (1959). Convergent and discriminant validation by the multitrait-multimethod matrix. Psychological Bulletin, 56: 81-105.

Cohen, J., \& Cohen, P. (1983). Applied multiple regression/ correlation analysis for the behavioral sciences. Hillsdale, NJ: Lawrence Erlbaum.

Cook, T.D. (1985). Postpositivist critical multiplism. In Shotland, L. \& Mark, M.M., (Eds.), Social science and social policy, 221-62. Beverly Hills, CA: Sage.

Cook, T.D. (1993). A quasi-sampling theory of the generalization of causal relations. In Sechrest, L.B., \& Scott, A.G., (Eds.), Understanding causes and generalizing about them. New Directions for Program Evaluation, No. 57. San Francisco: Jossey-Bass, 39-82.

Cook, T.D., \& Campbell, D.T. (1979). Quasi-experimentation: Design and analysis issues in field settings. Boston, MA: Houghton Mifflin.

Daly, M., \& Wilson, M. (1988). Homicide. New York, NY: Aldine de Gruyter.

Daly, M., \& Wilson, M. (1996). Evolutionary psychology of homicide. Demos, Dec. 8, $39-45$.

Diaz-Guerrero, R. (1975). Psychology of Mexicans: Culture and personality. Austin, TX: University of Texas.

Dawes, R.M. (1988). Rational choice in an uncertain world. New York, NY: Harcourt Brace Jovanovich..

Dawes, R.M. (1993). Prediction of the future versus an understanding of the past: A basic asymmetry. American Journal of Psychology, 106(1), 1-24.

Dawes, R.M. (1994). House of cards. New York, NY: Free Press.

Figueredo, A.J., \& McCloskey, L.A. (1993). Sex, money, and paternity: The evolutionary psychology of domestic violence. Ethology and Sociobiology, 14(6), 353-379.

Figueredo, A.J., McKnight, P.E., McKnight, K.M., \& Sidani, S. (2000). Multivariate modeling of missing data within and across assessment waves. Addiction, 95 (Supplement 3), S361-S380.

Figueredo, A.J., Corral-Verdugo, V., Frías-Armenta, M., Bachar, K.J., White, J., McNeill, P.L., Kirsner, B.R., \& Castell-Ruíz, I.P. (2001). Blood, solidarity, status, and honor: The sexual balance of power and spousal abuse in Sonora, Mexico. Evolution and Human Behavior, 22, 295-328.

Figueredo, A.J., Tal, I.R., McNeill, P., Guillén, A (2004). Farmers, herders, and fishers: The ecology of revenge. Evolution and Human Behavior, 25(5), 336-353.

Figueredo, A.J., Brumbach, B.H., Jones, D.N., Sefcek, J.A., Vásquez, G., \& Jacobs, W.J. (2007). Ecological constraints on mating tactics. In Geher, G., \& Miller, G.F., (Eds.), Mating Intelligence: Sex, Relationships and the Mind's Reproductive System (pp. 335-361). Mahwah, NJ: Lawrence Erlbaum.

Figueredo, A.J., \& Gorsuch, R. (2007). Assortative mating in the Jewel wasp: 2. Sequential canonical analysis as an exploratory form of path analysis. Journal of the Arizona Nevada Academy of Science, 39(2), 59-64.

Journal of Social, Evolutionary, and Cultural Psychology - ISSN 1933-5377 - volume 3 (1) 2009. 
García-Figueroa, G., Piñeda-Pablos, N., Sandoval-Godoy, S., Wong-González, P., Enriquez-Acosta, J., \& Fuentes-Fierro, A. (2002). Sonora frente al siglo XXI, Religión, laicidad y valores. Hermosillo, Sonora: Editorial Colegio de Sonora y UNISON.

Gottfredson, M.R., \& Hirschi, T. (1990). A General Theory of Crime. Stanford, CA: Stanford University Press.

Hamilton, M. (1959). The assessment of anxiety states by ratings. British Journal of Medical Psychology, 32, 50-55.

Hamilton, M. (1980). Rating depressive patients. Journal of Clinical Psychiatry, 41, 21 24.

Hamilton, M. (1985). The course of depression and depressive symptoms: A review and analysis. Integrative Psychiatry, 3, 151-152.

Irons, W. (1998). Adaptively relevant environments versus the environment of evolutionary adaptedness. Evolutionary Anthropology, 6(6), 194-204.

Kirsner, B.R., Figueredo, A.J., \& Jacobs, W.J. (2003). Self, friends, and lovers: Structural relations among Beck Depression Inventory scores and perceived mate values. Journal of Affective Disorders, 75, 131-148.

Laughlin, R. (2005). A Different Universe: Reinventing Physics from the Bottom Down. New York, NY: Basic Books.

Lumsden, C.J. \& Wilson, E.O. (1981). Genes, Mind, and Culture: The Coevolutionary Process. Cambridge, MA: Harvard University Press.

Mayr, E. (1982). The Growth of Biological Thought. Cambridge, MA: Belknap Press of Harvard University Press.

McCloskey, L.A., Figueredo, A.J., \& Koss, M.P. (1995). The effects of systemic family violence on children's mental health. Child Development, 66, 1239-1261.

McKnight, P.E., McKnight, K.M., Sidani, S. \& Figueredo, A.J. (2007). Missing Data: A Gentle Introduction. New York, NY: Guilford.

Nisbett, R.E., \& Cohen, D. (1996). Culture of honor: The psychology of violence in the South. Boulder, CO: Westview Press.

Reich, W., Earls, F., Frankel, O., \& Shayka, J.J. (1993). Psychopathology in children of alcoholics. American Academy of Child and Adolescent Psychiatry, 32, 9951002.

Reich, W., \& Herjanic, B. (1989). The Diagnostic Interview for Children and Adolescents (DICA). Unpublished manuscript, Department of Psychiatry, Washington University, St. Louis, MO.

Richerson, P.J., \& Boyd., R. (1998). The evolution of human ultra-sociality. In I. EiblEibesfeldt and F.K. Salter, (eds.), Indoctrinability, Ideology and Warfare, pp. 7196. New York: Berghahn Books.

Richerson, P.J., \& Boyd., R. (1999). Complex societies: the evolutionary origins of a crude superorganism. Human Nature, 10, 253-289.

Richerson, P.J., \& Boyd., R. (2001a). Institutional evolution in the Holocene: the rise of complex societies. In W.G. Runciman, (Ed.), The Origin of Human Social Institutions, pp. 197-204. Proceedings of the British Academy 110.

Journal of Social, Evolutionary, and Cultural Psychology - ISSN 1933-5377 - volume 3 (1) 2009. 
Richerson, P.J., \& Boyd., R. (2001b). The evolution of subjective commitment to groups: A tribal instincts hypothesis. In R.M. Nesse, (Ed.), The Evolution and the Capacity for Subjective Commitment, pp. 186-220. Russell Sage.

SAS Institute, Inc. (1989). SAS Language and Procedures: Usage, Version 6, First Edition. Cary, NC: SAS Institute.

Straus, M.A. (1979). Measuring intrafamily conflict and violence: The Conflict Tactics scales. Journal of Marriage and the Family, 41, 75-88.

Straus, M.A. (1990a). Injury and frequency of assault and the "representative sample fallacy" in measuring wife beating and child abuse. In Straus, M.A., \& Gelles, R.J., (Eds.), Physical violence in American families (pp. 75-91). New Brunswick, NJ: Transaction Publishers.

Straus, M.A. (1990b). The Conflict Tactics scales and its critics: An evaluation and new data on validity and reliability. In Straus, M.A., \& Gelles, R.J., (Eds.), Physical violence in American families (pp. 49-73). New Brunswick, NJ: Transaction Publishers.

Tjaden, P., \& Thoennes, N. (1998). Prevalence, incidence, and consequences of violence against women: Findings from the National Violence Against Women Survey. National Institute of Justice Centers for Disease Control and Prevention Research in Brief (pp. 1-16). Washington, DC: U.S. Dept. of Justice, Office of Justice Programs, National Institute of Justice.

Tooby, J., \& Cosmides, L. (1992). The psychological foundations of culture. In Barkow, J.H., Cosmides, L., \& Tooby, J., (Eds), The Adapted Mind: Evolutionary Psychology and the Generation of Culture, pp. 3-15. Oxford: Oxford Univ. Press.

United Nations Development Programme. (2007). Human Development Report 2007/2008: Fighting climate change: Human solidarity in a divided world. New York, NY: United Nations Development Programme.

Vega-Robles, I. (2001). Desarrollo humano, género y salud en Centroamérica: El caso de Costa Rica. Anuario de Estudios Centroamericanos, 27(002), 221-33.

Vega-Robles, I. (2007). Relaciones de equidad entre hombres y mujeres: Análisis crítico del entorno familiar. Actualidades en Psicología, 21, 59-78.

White, J.W., Smith, P.H., Koss, M.P., \& Figueredo, A.J. (2000). Intimate partner aggression: What have we learned? Commentary on Archer's meta-analysis. Psychological Bulletin, 126(5), 690-696.

Journal of Social, Evolutionary, and Cultural Psychology - ISSN 1933-5377 - volume 3 (1) 2009. 